\title{
Stroke Mortality, Clinical Presentation and Day of Arrival: The Atherosclerosis Risk in Communities (ARIC) Study
}

\author{
Emily C. O'Brien, ${ }^{1}$ Kathryn M. Rose, ${ }^{1}$ Eyal Shahar, ${ }^{2}$ and Wayne D. Rosamond ${ }^{1}$ \\ ${ }^{1}$ Department of Epidemiology, Gillings School of Global Public Health, University of North Carolina at Chapel Hill, \\ Chapel Hill, NC 27514-3526, USA \\ ${ }^{2}$ Division of Epidemiology and Biostatistics, Mel and Enid Zuckerman College of Public Health, University of Arizona, \\ Tucson 85711, USA \\ Correspondence should be addressed to Emily C. O’Brien, ecobrien@unc.edu
}

Received 24 January 2011; Accepted 7 March 2011

Academic Editor: G. J. Hankey

Copyright ( $) 2011$ Emily C. O’Brien et al. This is an open access article distributed under the Creative Commons Attribution License, which permits unrestricted use, distribution, and reproduction in any medium, provided the original work is properly cited.

\begin{abstract}
Background. Recent studies report that acute stroke patients who present to the hospital on weekends have higher rates of 28-day mortality than similar patients who arrive during the week. However, how this association is related to clinical presentation and stroke type has not been systematically investigated. Methods and Results. We examined the association between day of arrival and 28-day mortality in 929 validated stroke events in the ARIC cohort from 1987-2004. Weekend arrival was defined as any arrival time from midnight Friday until midnight Sunday. Mortality was defined as all-cause fatal events from the day of arrival through the 28th day of followup. The presence or absence of thirteen stroke signs and symptoms were obtained through medical record review for each event. Binomial logistic regression was used to estimate odds ratios and 95\% confidence intervals (OR; 95\% CI) for the association between weekend arrival and 28-day mortality for all stroke events and for stroke subtypes. The overall risk of 28 -day mortality was $9.6 \%$ for weekday strokes and $10.1 \%$ for weekend strokes. In models controlling for patient demographics, clinical risk factors, and event year, weekend arrival was not associated with 28-day mortality $(0.87 ; 0.51,1.50)$. When stratified by stroke type, weekend arrival was not associated with increased odds of mortality for ischemic $(1.17,0.62,2.23)$ or hemorrhagic $(0.37 ; 0.11,1.26)$ stroke patients. Conclusions. Presence or absence of thirteen signs and symptoms was similar for weekday patients and weekend patients when stratified by stroke type. Weekend arrival was not associated with 28 -day all-cause mortality or differences in symptom presentation for strokes in this cohort.
\end{abstract}

\section{Introduction}

Acute stroke is a leading cause of death and disability in the United States. The incidence of stroke is estimated at 750,000 cases per year, and stroke incidence has been shown to increase during weekends [1-4]. Recent studies from Canada, Taiwan, and the United States have reported increased risk of mortality in acute stroke patients arriving to the hospital on the weekend compared to those arriving during the week [5-8]. However, evidence for this "weekend effect" has been inconsistent, with studies from Ontario and California documenting no increase in in-hospital mortality among patients arriving on the weekend $[9,10]$. Additionally, few studies have examined the association between weekend arrival and event characteristics such as symptom presentation. One study of in-hospital mortality in intensive care unit (ICU) patients found no increase in mortality risk in off-hours patients after adjustment for initial disease severity [11]. In a study of patients with acute coronary syndrome (ACS), weekend cases were found to be more severe than weekday cases [12]. Reported increases in mortality risk among weekend stroke patients may be confounded by differences in clinical presentation between weekday and weekend patients.

Our study examined the association between weekend hospital arrival and 28-day mortality in 929 validated stroke events in the atherosclerosis risk in communities (ARIC) study cohort. Additionally, we assessed the impact of various 
baseline patient demographic and behavioral characteristics on both stroke incidence and 28-day stroke mortality associated with weekend hospital arrival. Lastly, we examined the hypothesis that weekend patients differ from weekday patients in the number and type of symptoms with which they present.

\section{Materials and Methods}

2.1. Study Population. The atherosclerosis risk in communities (ARIC) study is an ongoing, prospective, longitudinal study conducted in four U.S. communities: Forsyth County, North Carolina; Jackson, Mississippi; 8 suburbs of Minneapolis, Minnesota; and Washington County, Maryland. A cohort of 15,792 men and women completed baseline examinations from 1987 to 1989 . Clinic visits were conducted every three years through 1998. Hospitalizations were ascertained through annual telephone interviews and surveillance of hospitals in the four communities. Additional details of the study design have been published elsewhere [13].

2.2. Exclusions. Of the 15,972 ARIC cohort members with follow-up data through 2004, 1659 possible stroke events were identified. Of these, 138 events were excluded because of history of stroke at baseline ( $n=51$ cohort members). Events were excluded from the analysis if the event was not validated as a definite or probable stroke $(n=578)$. Ten deaths occurring out of hospital with stroke listed as the underlying cause of death were excluded. We also excluded black subjects from Washington County, Maryland $(n=2)$, and subjects who were not classified as black or white $(n=2)$. After these exclusions, we identified 929 definite or probable strokes in 781 cohort members for analysis.

2.3. Variable Definitions. Weekend arrival was defined as arrival to the hospital from midnight Friday to midnight Sunday. Mortality was defined as all-cause fatal events from the day of hospital arrival through the 28th day of follow-up. Individual stroke events were stratified into two types, ischemic (including embolic and thrombotic strokes) or hemorrhagic (including subarachnoid and intracerebral hemorrhages), as validated through physician review of the medical record associated with that admission [13]. The first stroke recorded for each cohort member without a prior history of stroke at baseline was classified as an incident stroke, with subsequent strokes classified as recurrent. To account for variation in the number and types of diseases present in each subject, the Charlson-Deyo comorbidity index was calculated using International Classification of Diseases ninth edition (ICD-9) discharge codes recorded for each event [14]. This index is a summary score representing the presence or absence of 17 distinct medical conditions, with a higher score indicating a greater burden of comorbidity associated with that hospitalization [15]. Symptom onset to brain imaging time (CT) was categorized as $\leq 24$ hours or $>24$ hours. Event year was classified into four categories based on quartile distribution of stroke events in the ARIC cohort. Alcohol drinking and cigarette smoking status were based on self-report and both defined as current drinker or smoker or not currently a drinker or smoker. Cigarette years of smoking was defined as the average number of cigarettes smoked per year times the number of years smoked. Presence or absence of thirteen stroke signs and symptoms (cranial nerve palsy, vertigo, diplopia, convulsions, severe headache, gait disturbance, hemianopia, loss of facial sensation, coma, aphasia, loss of extremity sensation, dysphagia, facial paresis, extremity paresis) was abstracted from the medical record. Analyses of signs and symptoms in relation to weekend hospital arrival were stratified by stroke type.

2.4. Statistical Methods and Analysis. Binomial logistic regression was used to estimate odds ratios (OR) and 95\% confidence intervals (CI) for the association between weekend hospital arrival and 28-day mortality for all stroke events and for events within each stroke type. All variables were coded using binary indicator variables, with the exception of cigarette years of smoking and age, both of which were coded as continuous. Interaction with the main exposure was assessed for all covariates using a likelihood ratio test at alpha level 0.10. Because events are nested within patients, there is potential for underestimation of standard errors. We utilized a multilevel modeling approach that accounted for the nesting of events within patients. These models produced similar results as those of the standard regression analyses, thus we present the original models without the multilevel modeling approach. SAS version 9.1 was used for all analyses (SAS Institute, Cary, NC).

\section{Results}

Of the 929 validated stroke events occurring during the study period, $218(23 \%)$ patients arrived at the hospital during the weekend, and $711(77 \%)$ arrived during the week. The baseline characteristics of the study population are shown in Table 1. Overall, few differences were observed between baseline characteristics of patients arriving at the hospital on the weekend versus the weekday. Patients arriving at the hospital on the weekend were more likely to be incident than recurrent strokes and were less likely to be current drinkers than patients arriving during the week, though neither of these comparisons was statistically significant.

The overall risk of 28 -day mortality was $9.7 \%$. Crude mortality risks were similar for weekend and weekday arrivals ( $10.1 \%$ versus $9.6 \%$, resp.). Risk of 28 -day mortality for hemorrhagic strokes was significantly higher than for ischemic stokes (35.2\% versus $6.3 \%$, resp.). Mean length of stay was approximately one day longer for weekday patients than for weekend patients.

As shown in Figures 1 (ischemic strokes) and 2 (hemorrhagic strokes), symptom prevalence did not differ significantly between patients arriving at the hospital on the weekend compared to those arriving during the week for hemorrhagic or ischemic stroke patients.

The results of the logistic regression analysis of weekend hospital arrival and 28-day mortality are shown in Table 2. Minimally adjusted models controlled for age, race, center, and gender. Fully adjusted models controlled for all of these variables in addition to comorbidities, smoking status, 
TABLE 1: Baseline characteristics (1987-1989) of stroke patients by day of hospital arrival in the atherosclerosis risk in communities (ARIC) Study.

\begin{tabular}{|c|c|c|c|}
\hline Study variables & Weekday arrivals $(n=711,77 \%)$ & Weekend* arrivals $(n=218,23 \%)$ & $P$ value ${ }^{\dagger}$ \\
\hline Mean age in years $(95 \% \mathrm{CI})$ & $66.4(65.8,66.9)$ & $66.9(66.0,67.8)$ & \\
\hline \multicolumn{4}{|l|}{ Gender } \\
\hline Male & $348(49)$ & $108(50)$ & \multirow[t]{2}{*}{.88} \\
\hline Female & $363(51)$ & $110(50)$ & \\
\hline \multicolumn{4}{|l|}{ Race } \\
\hline White & $394(56)$ & $116(54)$ & \multirow[t]{2}{*}{.66} \\
\hline African American & $314(44)$ & $99(46)$ & \\
\hline \multicolumn{4}{|l|}{ Center } \\
\hline Forsyth County & $134(19)$ & $58(27)$ & \multirow[t]{4}{*}{.05} \\
\hline Jackson & $285(40)$ & $83(38)$ & \\
\hline Minneapolis & $122(17)$ & $38(17)$ & \\
\hline Washington County & $170(24)$ & $39(18)$ & \\
\hline \multicolumn{4}{|l|}{ Race center category } \\
\hline Forsyth blacks & $29(4)$ & $16(7)$ & \multirow[t]{5}{*}{.07} \\
\hline Forsyth whites & $10515)$ & $42(20)$ & \\
\hline Minneapolis whites & $119(17)$ & $35(16)$ & \\
\hline Washington Co. whites & $170(24)$ & $39(18)$ & \\
\hline Jackson blacks & $285(40)$ & $83(39)$ & \\
\hline \multicolumn{4}{|l|}{ Stroke type } \\
\hline Ischemic & $629(89)$ & $192(88)$ & \multirow[t]{2}{*}{.87} \\
\hline Hemorrhagic & $82(11)$ & $26(12)$ & \\
\hline \multicolumn{4}{|l|}{ Stroke event } \\
\hline Incident & $589(83)$ & $191(88)$ & \multirow[t]{2}{*}{.09} \\
\hline Recurrent & $122(17)$ & $27(12)$ & \\
\hline \multicolumn{4}{|l|}{ Onset to brain imaging } \\
\hline$<24$ hours & $455(71)$ & $144(71)$ & \multirow[t]{2}{*}{.84} \\
\hline$\geq 24$ hours & $183(29)$ & $60(29)$ & \\
\hline Mean length of stay $(95 \% \mathrm{CI})$ & $10.3(9.4,11.2)$ & $9.1(7.9,10.3)$ & \\
\hline Current drinker & $332(48)$ & $99(46)$ & .62 \\
\hline Current smoker & $241(34)$ & $76(35)$ & .80 \\
\hline Mean cigarette years of smoking & $396.4(359.6,433.2)$ & $377.4(313.5,441.2)$ & \\
\hline Charlson comorbidity score & $2.28(2.20,2.37)$ & $2.22(2.08,2.37)$ & .89 \\
\hline Death within 28 days & $68(9.6)$ & $22(10.1)$ & .82 \\
\hline \multicolumn{4}{|l|}{ Event year } \\
\hline 1987-1994 & $170(24)$ & $51(23)$ & \multirow[t]{4}{*}{.76} \\
\hline 1995-1998 & $192(26)$ & $64(29)$ & \\
\hline 1999-2001 & $179(25)$ & $48(22)$ & \\
\hline 2002-2004 & $170(24)$ & $55(25)$ & \\
\hline
\end{tabular}

* Weekend defined as any arrival time from midnight Friday to midnight Sunday.

${ }^{\dagger}$ Two-sided chi-squared test of equal proportions.

drinking status, onset to imaging time, onset year, and recurrent stroke. Overall, weekend arrival was not associated with 28 -day mortality in crude $(1.06 ; 0.64,1.76)$, minimally adjusted $(1.07 ; 0.64,1.78)$, or fully adjusted models $(0.87$; $0.51,1.50)$. In crude models stratified by stroke type, weekend arrival was associated with a decreased risk of 28-day mortality among hemorrhagic stroke patients $(0.41$; $0.16,1.06)$, and an increased risk of 28 -day mortality in ischemic stroke patients $(1.36 ; 0.73,2.53)$. A similar pattern was observed by stroke type in minimally adjusted models (ischemic: $1.39 ; 0,74,2.62$; hemorrhagic: $0.42 ; 0.16,1.13$ ) and in fully adjusted models (ischemic: $1.17 ; 0.60,2.23$; hemorrhagic: $0.37 ; 0.11,1.26)$. However, none of these estimates reached statistical significance.

In order to examine the effect of exposure classification on mortality, we performed a sensitivity analysis in which "weekend arrival" was redefined as any hospital arrival from $6 \mathrm{pm}$ Friday to 7 am Monday. The results of this analysis are shown in Table 3. The effect of weekend arrival on odds of death within 28 days was slightly attenuated for both 
TABLE 2: Logistic regression results. Weekend effect* among stroke patients overall and by stroke type in the atherosclerosis risk in communities (ARIC) study (1987-1989).

\begin{tabular}{|c|c|c|c|}
\hline \multirow{3}{*}{ Model description } & \multicolumn{3}{|c|}{ Odds of 28-day mortality comparing weekend patients to weekday } \\
\hline & & patients (OR; 95\% CI & \\
\hline & Overall $(N=929)$ & Ischemic $(N=821)$ & $\begin{array}{l}\text { Hemorrhagic } \\
(N=108)\end{array}$ \\
\hline Model 1. Crude & $1.06(0.64,1.76)$ & $1.36(0.73,2.53)$ & $0.61(0.23,1.61)$ \\
\hline Model 2. Model $1+$ age, race* center, sex & $1.07(0.64,1.78)$ & $1.39(0.74,2.62)$ & $0.42(0.16,1.13)$ \\
\hline $\begin{array}{l}\text { Model 3. Model } 2+\text { Comorbidities }^{\dagger} \text {, smoking status, drinking } \\
\text { status, onset to imaging time }{ }^{\ddagger} \text {, event year, recurrent stroke }\end{array}$ & $0.87(0.51,1.50)$ & $1.17(0.60,2.23)$ & $0.37(0.11,1.26)$ \\
\hline
\end{tabular}

${ }^{*}$ Weekend defined as any arrival time from midnight Friday to midnight Sunday.

${ }^{\dagger}$ Charlson comorbidity index score of $\leq 1,2-3,>3$.

$\ddagger 24$ hours or $\geq 24$ hours.

TABLE 3: Sensitivity analysis results. Weekend effect* among stroke patients overall and by stroke type in the atherosclerosis risk in communities (ARIC) study (1987-1989).

Odds of 28-day mortality comparing weekend patients to weekday

Model description patients (OR; 95\% CI)

\begin{tabular}{|c|c|c|c|}
\hline & Overall $(N=929)$ & Ischemic $(N=821)$ & $\begin{array}{l}\text { Hemorrhagic } \\
\quad(N=108)\end{array}$ \\
\hline Model 1. Crude & $0.85(0.52,1.40)$ & $1.14(0.62,2.09)$ & $0.41(0.16,1.06)$ \\
\hline Model 2. Model $1+$ age, race* center, sex & $0.86(0.52,1.41)$ & $1.14(0.62,2.11)$ & $0.42(0.16,1.13)$ \\
\hline $\begin{array}{l}\text { Model 3. Model } 2+\text { Comorbidities }{ }^{\dagger} \text {, smoking status, drinking } \\
\text { status, onset to imaging time }{ }^{\ddagger} \text {, event year, recurrent stroke }\end{array}$ & $0.70(0.42,1.20)$ & $0.98(0.51,1.89)$ & $0.30(0.09,1.00)$ \\
\hline
\end{tabular}

${ }^{*}$ Weekend defined as any arrival time from $6 \mathrm{pm}$ Friday to 7 am Monday.

${ }^{\dagger}$ Charlson comorbidity index score of $\leq 1,2-3,>3$.

$\ddagger 24$ hours or $\geq 24$ hours.

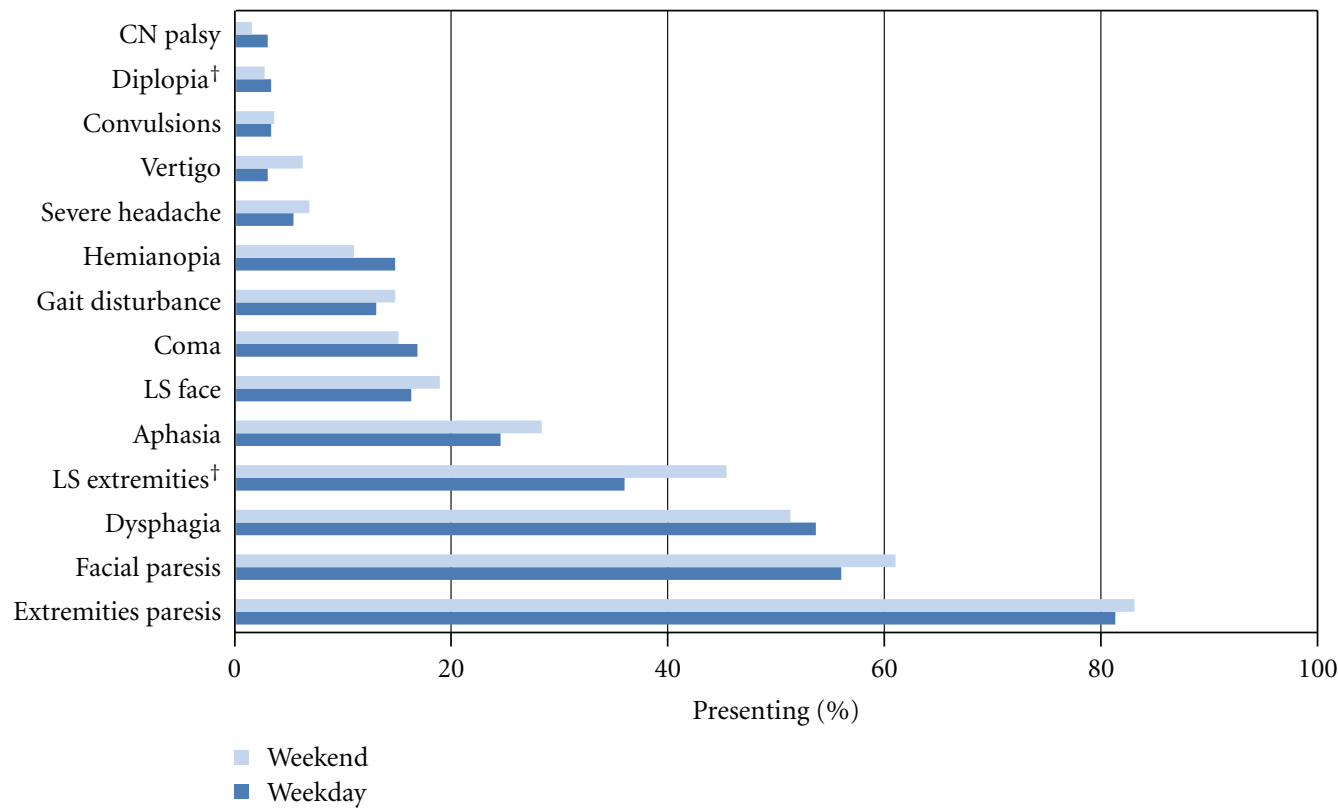

FIGURE 1: Differences in percent of ischemic strokes presenting with selected symptoms on weekends* and weekdays in the atherosclerosis risk in communities (ARIC) study (1987-2004). Abbreviations: CN palsy: cranial nerve palsy; LS face: loss of sensation in face; LS extremities: loss of sensation in extremities. ${ }^{*}$ Weekend defined as any hospital arrival time from midnight Friday to midnight Sunday, ${ }^{\dagger} P<.05$ (two-sided chi-squared test for equal proportions). 
TABLE 4: Baseline characteristics (1987-1989) of stroke patients by stroke type in the atherosclerosis risk in communities (ARIC) study.

\begin{tabular}{|c|c|c|c|}
\hline Variables & Ischemic $(n=821,88 \%)$ & Hemorrhagic $(n=108,12 \%)$ & $P$ value ${ }^{\dagger}$ \\
\hline \multicolumn{4}{|l|}{ Arrival day } \\
\hline Weekday & $629(77)$ & $82(76)$ & \multirow[t]{3}{*}{.87} \\
\hline Weekend* & $192(23)$ & $26(24)$ & \\
\hline Mean age in years $(95 \% \mathrm{CI})$ & $66.8(66.3,67.2)$ & $64.4(62.9,65.9)$ & \\
\hline \multicolumn{4}{|l|}{ Gender } \\
\hline Male & $414(50)$ & $42(39)$ & \multirow[t]{2}{*}{.02} \\
\hline Female & $407(50)$ & $66(61)$ & \\
\hline \multicolumn{4}{|l|}{ Race } \\
\hline White & $463(57)$ & $47(44)$ & \multirow[t]{2}{*}{.009} \\
\hline African American & $352(43)$ & $61(56)$ & \\
\hline \multicolumn{4}{|l|}{ Center } \\
\hline Forsyth County & $171(21)$ & $21(19)$ & \multirow[t]{4}{*}{.01} \\
\hline Jackson & $310(38)$ & $58(54)$ & \\
\hline Minneapolis & $147(18)$ & $13(12)$ & \\
\hline Washington County & $193(23)$ & $16(15)$ & \\
\hline \multicolumn{4}{|l|}{ Race center category } \\
\hline Forsyth blacks & $42(5)$ & $3(3)$ & \multirow[t]{5}{*}{.02} \\
\hline Forsyth whites & $129(16)$ & $18(17)$ & \\
\hline Minneapolis whites & $141(17)$ & $13(12)$ & \\
\hline Washington Co. whites & $193(24)$ & $16(15)$ & \\
\hline Jackson blacks & $310(38)$ & $58(54)$ & \\
\hline \multicolumn{4}{|l|}{ Stroke event } \\
\hline Incident & $682(83)$ & $98(91)$ & \multirow[t]{2}{*}{.04} \\
\hline Recurrent & $139(17)$ & $10(9)$ & \\
\hline \multicolumn{4}{|l|}{ Onset to brain imaging } \\
\hline$<24$ hours & $515(70)$ & $84(82)$ & \multirow[t]{2}{*}{.005} \\
\hline$\geq 24$ hours & $225(30)$ & $18(18)$ & \\
\hline Mean length of stay $(95 \% \mathrm{CI})$ & $9.6(8.9,10.4)$ & $13.0(10.4,15.6)$ & \\
\hline Current drinker & $378(46.8)$ & $53(50)$ & .60 \\
\hline Current smoker & $276(33.7)$ & $41(38)$ & .38 \\
\hline Mean cigarette years of smoking ( $95 \% \mathrm{CI})$ & $395(361,429)$ & $366.4(277,455)$ & \\
\hline Charlson comorbidity score (95\% CI) & $2.3(2.3,2.4)$ & $1.9(1.7,2.1)$ & \\
\hline Death within 28 days & $52(6.3)$ & $38(35)$ & $<.0001$ \\
\hline \multicolumn{4}{|l|}{ Event year } \\
\hline 1987-1994 & $187(22.8)$ & $34(31)$ & \multirow[t]{4}{*}{.11} \\
\hline 1995-1998 & $224(27.3)$ & $32(30)$ & \\
\hline 1999-2001 & $204(24.9)$ & $23(21)$ & \\
\hline 2002-2004 & $206(25.0)$ & $19(18)$ & \\
\hline
\end{tabular}

*Weekend defined as any arrival time from midnight Friday to midnight Sunday.

† Two-sided chi-squared test of equal proportions.

ischemic and hemorrhagic stroke patients, but the respective directions of the effect remained unchanged.

Finally, we examined differences in baseline clinical characteristics between ischemic and hemorrhagic stroke patients. As shown in Table 4, ischemic stroke patients were more likely to be white, male, and current smokers. However, no differences in overall risk of 28-day mortality or in the proportion of patients arriving on the weekend were detected between ischemic and hemorrhagic stroke patients.

\section{Discussion}

We found that stroke patients in the ARIC study arriving to the hospital on weekends did not experience an increased risk of 28-day mortality compared to patients arriving during the week. Additionally, none of the baseline clinical characteristics of patients with a weekend hospital arrival differed statistically from those arriving during the week. Finally, when stratified by stroke type, weekend patients 


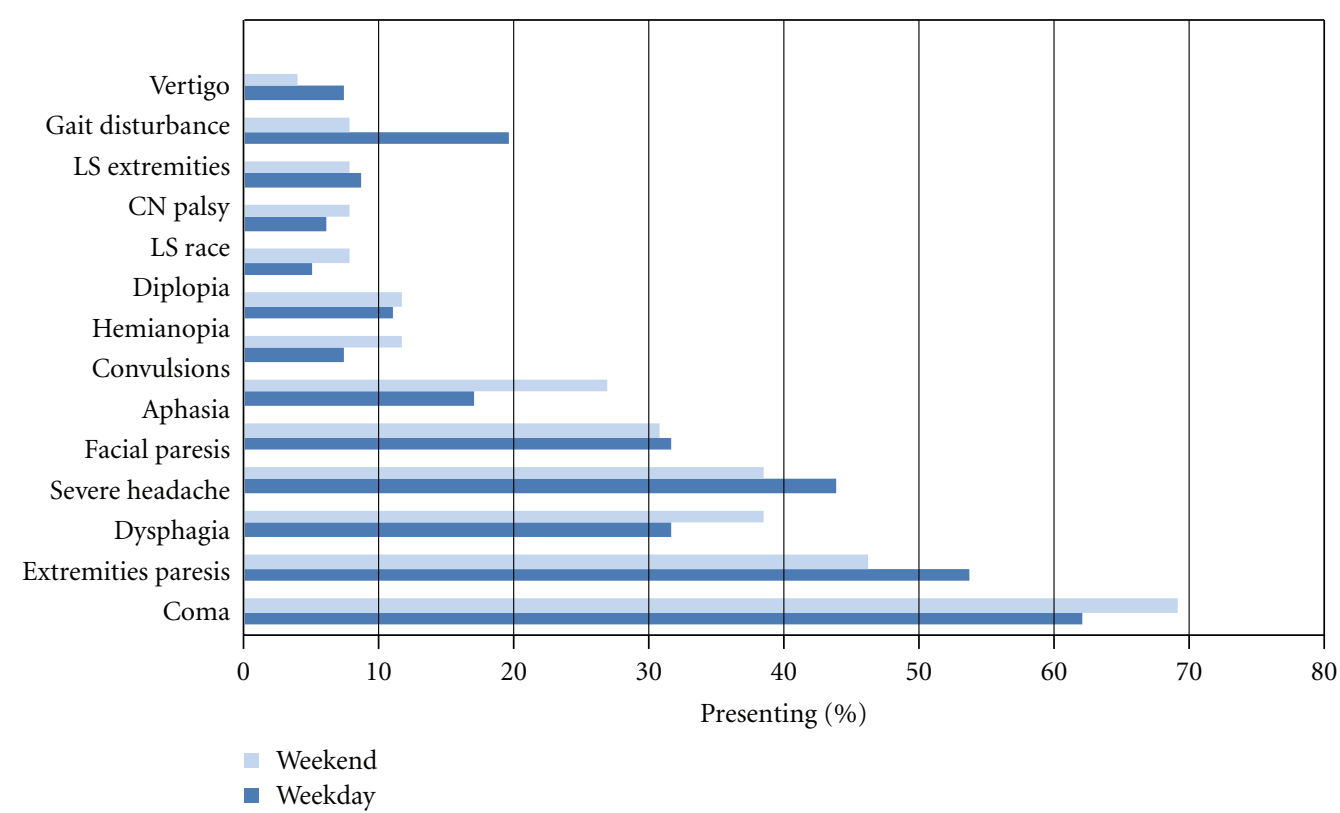

FIGURE 2: Differences in percent of hemorrhagic strokes presenting with selected symptoms on weekends* and weekdays in the atherosclerosis risk in communities (ARIC) study (1987-2004). Abbreviations: CN palsy: cranial nerve palsy; LS face: loss of sensation in face; LS extremities: loss of sensation in extremities. ${ }^{*}$ Weekend defined as any hospital arrival time from midnight Friday to midnight Sunday, ${ }^{\dagger} P<.05$ (two-sided chi-squared test for equal proportions).

presented with similar symptoms as patients arriving during the week.

One mechanism that has been proposed for the increased risk of mortality associated with weekend arrival is that patients arriving on weekends may experience more severe strokes than patients presenting during the week. In order to examine this hypothesis, we compared symptom presentation for weekend and weekday patients stratified by stroke type. We did not detect any statistically significant differences in symptoms in hemorrhagic stroke patients, and only two of thirteen symptoms in ischemic stroke patients were statistically different when comparing the proportion presenting on weekends versus weekdays. However, the absolute difference between the proportion of patients presenting with either of these symptoms was small. Another related hypothesis that weekend patients may differ from weekday patients in their respective numbers of comorbid conditions. We examined this theory by using discharge codes associated with hospitalization to calculate the Charlson comorbidity index for each event. We did not observe statistically significant differences in the mean or median number of comorbidities by weekend arrival status. Finally, stroke symptom recognition and speed with which patients present to the hospital after symptom onset may differ by education status. However, inclusion of a term for education in the logistic regression model (less than high school, high school, or greater) did not significantly alter our results.

Hospital staffing levels tend to be lower on the weekends than on weekdays [9]. Because of this, weekend emergency room patients may be less likely to receive invasive procedures and more likely to experience longer in-hospital delays [16-18]. One study of acute stroke patients in comprehensive stroke centers found no effect of weekend admission, which may be due to the availability of neuroimaging and specialists during off-hours [19]. Another analysis of acute ischemic stroke patients found no differences in receipt of t-PA between weekend and weekday patients [20]. Unfortunately, we do not have data on specific staffing levels at hospitals in our study. Additionally, only 8 patients received t-PA during the study period, so we were underpowered to examine differences in t-PA administration by day of hospital arrival.

4.1. Strengths. The ARIC cohort study is a well-characterized, biracial, and geographically diverse study population, with complete information on prestroke behaviors that is often lacking in studies examining day of hospital arrival. This study utilized data from physician-validated stroke events, so misclassification of stroke events was minimal relative to studies based on discharge diagnosis codes. Additionally, we had data on symptom presentation for all events and were thus able to examine a proxy for stroke severity, which is rarely available in larger studies.

4.2. Limitations. The sample size for our study was relatively small ( $n=929$ validated events). This limited our power to detect statistically significant differences in both mortality risk and baseline characteristics between weekend and weekday patients. We also analyzed the association between weekend arrival and all-cause mortality within 7 days instead of within 28 days of hospital arrival; however, the number of deaths occurring within seven days of hospital arrival was deemed too small to have sufficient power to detect any effect. We also did not have specific data on stroke severity. However, when using symptom presentation as a proxy 
for stroke severity, we did not see significant differences between weekday and weekend patients. Because the quality of care delivered to stroke patients can have an impact on stroke outcomes, some have proposed that hospitals which may be understaffed during weekend hours may deliver less prompt, high-quality care $[7,21]$. However, quality performance measures were not available in our study. We did evaluate the proportion of patients arriving at a hospital classified as teaching or nonteaching and did not detect any statistically significant differences between weekend hospital arrival patients and weekday hospital arrival patients by teaching status. Several studies have examined the effect of arriving to the hospital on holidays and "off-hours", including nights and weekends, to assess the impact of changes in hospital staffing and availability of specialists on stroke mortality $[22,23]$. Future studies wishing to examine the mechanism of any increased risk associated with weekend arrival should examine variation in hospital resources by both day and time of arrival. Additionally, more research is needed on the possible modification of the weekend effect on stroke mortality by current behavioral patterns.

\section{Conclusion}

In conclusion, we did not find statistically significant differences in baseline characteristics or mortality rates of patients arriving on the weekend as compared to those arriving during the week. We did not find an increased risk of 28day mortality among patients arriving to the hospital on weekends or off-hours. These results suggest that stroke type should be considered as a possible modifier of the effect of hospital arrival day in future studies of weekend arrival in acute stroke patients.

\section{Conflicts of Interests}

The authors declared that there is no conflict of interest.

\section{Acknowledgments}

This research was supported by the National Institutes of Health, NHLBI, and National Research Service Award training Grant 5-T32-HL007 (E. O’Brien). The ARIC study is carried out as a collaborative study supported by NHLBI contracts N01-HC-55015, N01-HC-55016, N01-HC-55018, N01-HC-55019, N01-HC-55020, N01-HC-55021, and N01HC-55022.

\section{References}

[1] H. Haapaniemi, M. Hillbom, and S. Juvela, "Weekend and holiday increase in the onset of ischemic stroke in young women," Stroke, vol. 27, no. 6, pp. 1023-1027, 1996.

[2] H. Wang, M. Sekine, X. Chen, and S. Kagamimori, "A study of weekly and seasonal variation of stroke onset," International Journal of Biometeorology, vol. 47, no. 1, pp. 13-20, 2002.

[3] W. Rosamond, K. Flegal, K. Furie et al., "Heart disease and stroke statistics-2008 update: a report from the American Heart Association Statistics Committee and Stroke Statistics
Subcommittee," Circulation, vol. 117, no. 4, pp. e25-e146, 2008.

[4] T. C. Turin, Y. Kita, Y. Murakami et al., "Increase of stroke incidence after weekend regardless of traditional risk factors: Takashima Stroke Registry, Japan; 1988-2003," Cerebrovascular Diseases, vol. 24, no. 4, pp. 328-337, 2007.

[5] G. Saposnik, A. Baibergenova, N. Bayer, and V. Hachinski, "Weekends: a dangerous time for having a stroke?" Stroke, vol. 38, no. 4, pp. 1211-1215, 2007.

[6] R. W. Crowley, H. K. Yeoh, G. J. Stukenborg, R. Medel, N. F. Kassell, and A. S. Dumont, "Influence of weekend hospital admission on short-term mortality after intracerebral hemorrhage," Stroke, vol. 40, no. 7, pp. 2387-2392, 2009.

[7] M. J. Reeves, E. Smith, G. Fonarow, A. Hernandez, W. Pan, and L. H. Schwamm, "Off-hour admission and in-hospital stroke case fatality in the get with the guidelines-stroke program," Stroke, vol. 40, no. 2, pp. 569-576, 2009.

[8] Y. C. Tung, G. M. Chang, and Y. H. Chen, "Associations of physician volume and weekend admissions with ischemic stroke outcome in Taiwan: a nationwide population-based study," Medical Care, vol. 47, no. 9, pp. 1018-1025, 2009.

[9] C. M. Bell and D. A. Redelmeier, "Mortality among patients admitted to hospitals on weekends as compared with weekdays," New England Journal of Medicine, vol. 345, no. 9, pp. 663-668, 2001.

[10] P. Cram, S. L. Hillis, M. Barnett, and G. E. Rosenthal, "Effects of weekend admission and hospital teaching status on inhospital mortality," American Journal of Medicine, vol. 117, no. 3, pp. 151-157, 2004.

[11] C. E. Luyt, A. Combes, P. Aegerter et al., "Mortality among patients admitted to intensive care units during weekday day shifts compared with "off" hours," Critical Care Medicine, vol. 35, no. 1, pp. 3-11, 2007.

[12] T. LaBounty, K. A. Eagle, R. Manfredini et al., "The impact of time and day on the presentation of acute coronary syndromes," Clinical Cardiology, vol. 29, no. 12, pp. 542-546, 2006.

[13] "The Atherosclerosis Risk in Communities (ARIC) Study: design and objectives," American Journal of Epidemiology, vol. 129, no. 4, pp. 687-702, 1989.

[14] R. Braun, A. Rybarz, M. Schulz, and R. Thierbach, "Introduction of the 9th revision of the international statistical classification of diseases, injuries and causes of death. 2," Zeitschrift fur Arztliche Fortbildung, vol. 72, no. 20, pp. 990995, 1978.

[15] M. E. Charlson, P. Pompei, K. L. Ales, and C. R. MacKenzie, "A new method of classifying prognostic comorbidity in longitudinal studies: development and validation," Journal of Chronic Diseases, vol. 40, no. 5, pp. 373-383, 1987.

[16] A. G. Rudd, A. Hoffman, C. Down, M. Pearson, and D. Lowe, "Access to stroke care in England, Wales and Northern Ireland: the effect of age, gender and weekend admission," Age and Ageing, vol. 36, no. 3, pp. 247-255, 2007.

[17] C. M. Bell and D. A. Redelmeier, "Waiting for urgent procedures on the weekend among emergently hospitalized patients," American Journal of Medicine, vol. 117, no. 3, pp. 175-181, 2004.

[18] W. J. Kostis, K. Demissie, S. W. Marcella, Y. H. Shao, A. C. Wilson, and A. E. Moreyra, "Weekend versus weekday admission and mortality from myocardial infarction," New England Journal of Medicine, vol. 356, no. 11, pp. 1099-1109, 2007. 
[19] K. C. Albright, R. Raman, K. Ernstrom et al., "Can comprehensive stroke centers erase the 'weekend effect'?" Cerebrovascular Diseases, vol. 27, no. 2, pp. 107-113, 2009.

[20] A. S. Kazley, D. G. Hillman, K. C. Johnston, and K. N. Simpson, "Hospital care for patients experiencing weekend vs weekday stroke: a comparison of quality and aggressiveness of care," Archives of Neurology, vol. 67, no. 1, pp. 39-44, 2010.

[21] M. Jauss, W. Oertel, J. Allendoerfer, B. Misselwitz, and H. Hamer, "Bias in request for medical care and impact on outcome during office and non-office hours in stroke patients," European Journal of Neurology, vol. 16, no. 10, pp. 1165-1167, 2009.

[22] R. Carandang, S. Seshadri, A. Beiser et al., "Trends in incidence, lifetime risk, severity, and 30-day mortality of stroke over the past 50 years," Journal of the American Medical Association, vol. 296, no. 24, pp. 2939-2946, 2006.

[23] P. Garot, J. M. Juliard, H. Benamer, and P. G. Steg, "Are the results of primary percutaneous transluminal coronary angioplasty for acute myocardial infarction different during the "off" hours?" American Journal of Cardiology, vol. 79, no. 11, pp. 1527-1529, 1997. 


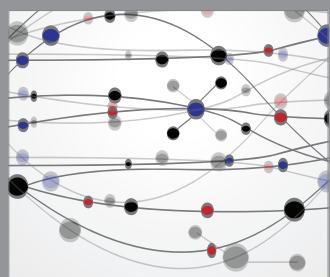

The Scientific World Journal
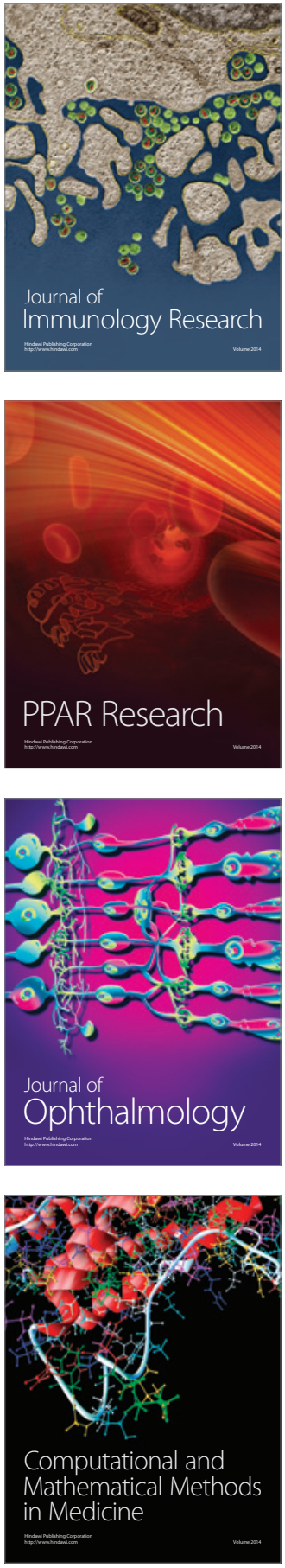

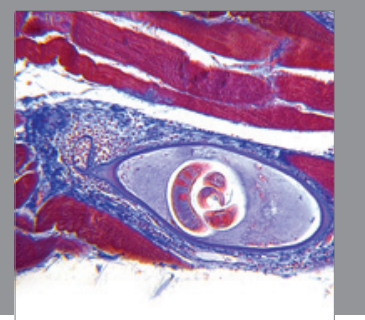

Gastroenterology

Research and Practice
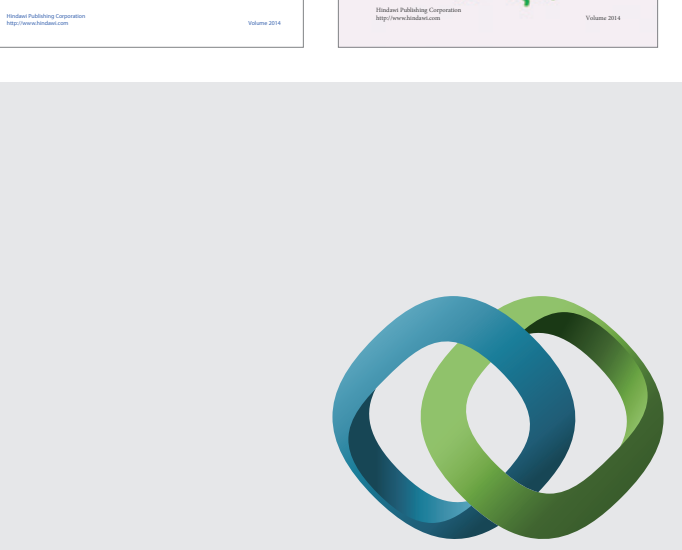

\section{Hindawi}

Submit your manuscripts at

http://www.hindawi.com
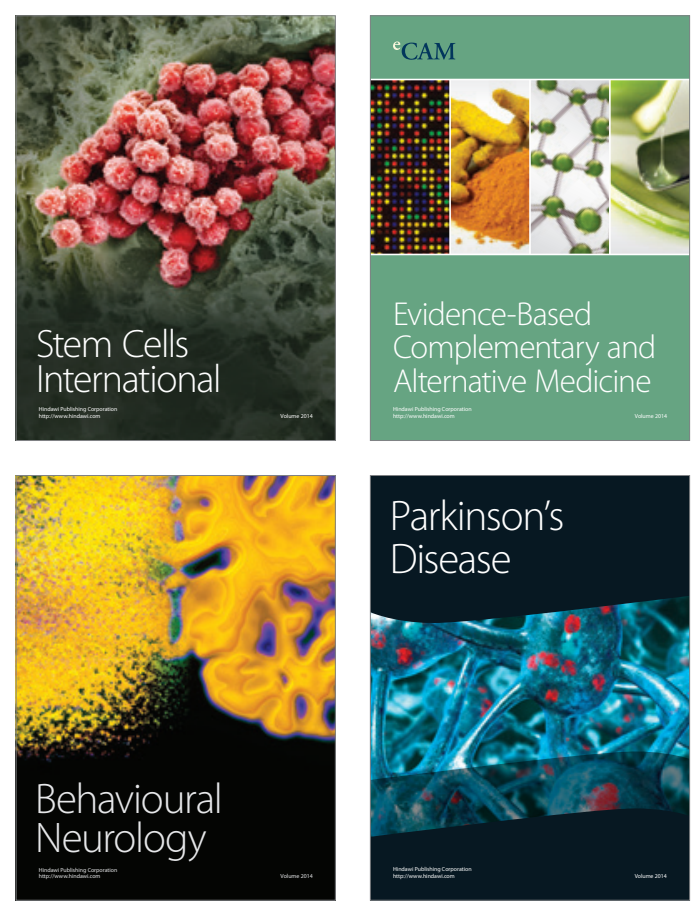

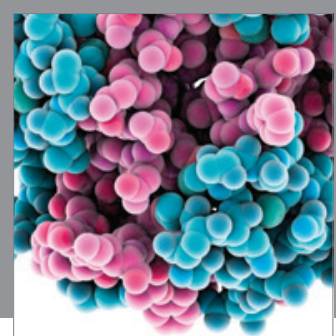

Journal of
Diabetes Research

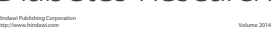

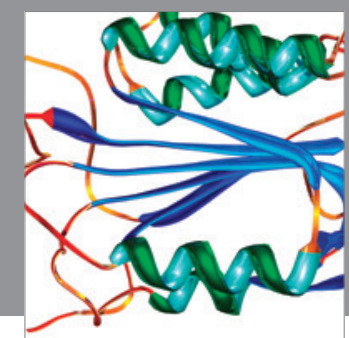

Disease Markers
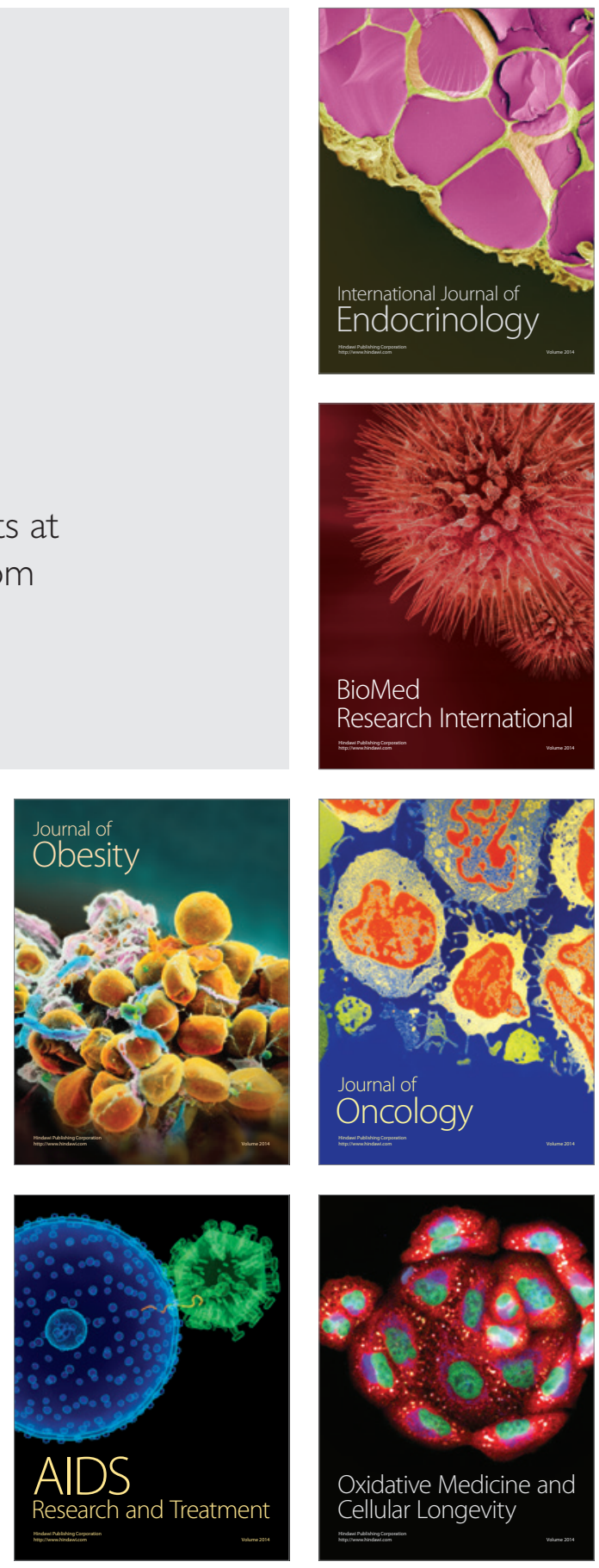